\title{
Subcutaneous Extraskeletal Osteosarcoma of the Head in a Dog: A Case Report
}

\author{
W Sugandhika Gothami ${ }^{1 *}$, Sugath Pemachandra' ${ }^{1}$, Kumudini Wasalaarachchi², Lasantha Ranasinghe ${ }^{1}$, Amal D \\ Premarathna $^{3}$ and Chathuri Kodithuwakku ${ }^{1}$ \\ ${ }^{1}$ City Pet Animal Hospital, Athurugiria, Sri Lanka \\ ${ }^{2}$ Consulant pathologist, Teaching hospital Colombo South, Sri Lanka \\ ${ }^{3}$ Department of Veterinary Pathobiology, University of Peradeniya, Sri Lanka
}

Received: 阱 July 14, 2018; Published: 阱July 25, 2018

*Corresponding author: W Sugandhika Gothami, Veterinary surgeon, City Pet Animal Hospital, Sri Lanka.

\begin{abstract}
This report describes the results of clinical, cytological and histopathological findings associated with subcutaneous extraskeletal osteosarcoma of a 05 years old Australian Silky Terrier. The tumor was located on the head above the frontal and parietal part of the skull. A definitive diagnosis was based on histological examination of the mass. Even though chemotherapy was suggested owner declined it therefore wide surgical resection of the tumor was performed with appropriate supportive therapy. However, the dog died few months after the initial presentation. To our knowledge, this case report is the first description of extraskeletal osteosarcoma of the head in a dog in Sri Lanka with the history of swelling on the head, lethargy, head pressing against objects and anorexia. Extraskeletal osteosarcoma should be considered in the differential diagnosis of soft tissue swelling in head in dogs. It is highly recommended to use advance diagnostic aids in order to rule out primary bone tumors.
\end{abstract}

Keywords: Extraskeletal osteosarcoma; Dog

Abbreviations: WHO: World Health Organization; OSA: Osteosarcom; MLO: Multilobular Osteochondr Osarcoma

\section{Introduction}

Osteosarcoma is the most common bone tumor in dogs, representing for more than $80 \%$ of malignant bone tumors [1]. It has higher ability to metastasis to visceral organs and especially to lungs [2,3]. It mainly occurs in large and giant breeds and often can be seen in appendicular skeleton, specifically at the metaphysial region of the long bones $[1,3,4]$. The presence of tumor in the axial skeleton (skull, rib, vertebrae, pelvis) has also been described $[3,5]$. Appendicular OSA is known to be more aggressive than axial ones with higher metastatic rate and higher tumor grade [1]. Extraskeletal osteosarcoma is very rare tumor in human and animals which arises in soft tissues (GIT, subcutaneous tissue, spleen, liver, skin, kidney, bladder, muscle, thyroid, eye and Mammary gland). It has also been reported in reproductive organs like testicles and vagina [6,7]. It is a malignant tumor of mesenchymal origin, producing osteoid which resemble histological features of primary osteosarcoma of bone but without any direct association to bony structures $[8,9]$. This present case study describes extremely rare subcutaneous extraskeletal osteosarcoma.

\section{Case Presentation}

A 5-year-old male intact Australian Silky Terrier was presented to the City Pet Animal Hospital, Athurugiriya, Sri Lanka, with the history of swelling on the head, lethargy, head pressing against objects and anorexia. On physical examination he was afebrile, and palpation of the swelling revealed it was hard but not painful. History revealed that there had been an injury caused by porcupine quill at the same site. Differential diagnoses include hematoma, granuloma and tumor. Radiography of the head evinced radiopaque mass above the skull with no evidence of adjacent bone involvement. An incision biopsy of the lesion $(10 \times 8 \times 5 \mathrm{~mm})$ was obtained and submitted in formal saline to the histopathology division of the Asiri Surgical Hospital, Colombo 05. 5 days after taking incision biopsy, surgery was performed to remove the tumor. The dog was sedated by Xylazine $(1 \mathrm{mg} / \mathrm{kg})$. The induction was achieved using Propafol $(4 \mathrm{mg} / \mathrm{kg}$ ) followed by maintenance doses of Propafol. As the tumor is embedded in the subcutaneous tissue, resection of tumor en bloc was not a possibility. Therefore, aggressive surgical resection of the tumor tissue in conjunction with chemotherapy was recommended. Histologically, it revealed polygonal to spindloid cells with hyperchromatic nuclei and prominent multiple nucleoli. Nucleus to cytoplasmic ratio was high with elevated atypical mitotic figures (Figure 1-3). The neoplastic cells produced irregular islands of well-developed osteoid and cells were located within osteoid lacunae. Clinical, radiological and cytological examination confirmed it to be an Osteosarcoma of extraskeletal origin. 


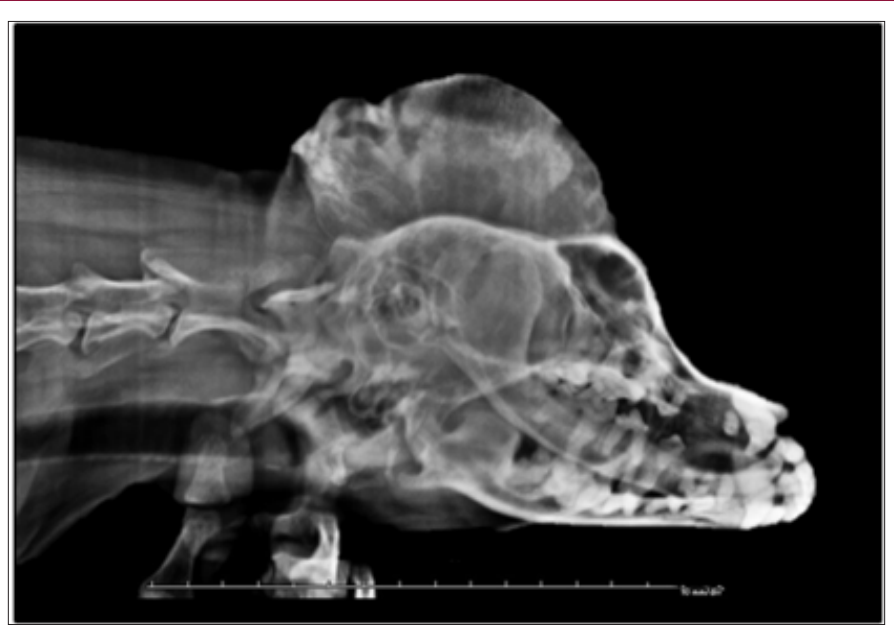

Figure 1: Radiograph of the head showing calcified mass above the skull.

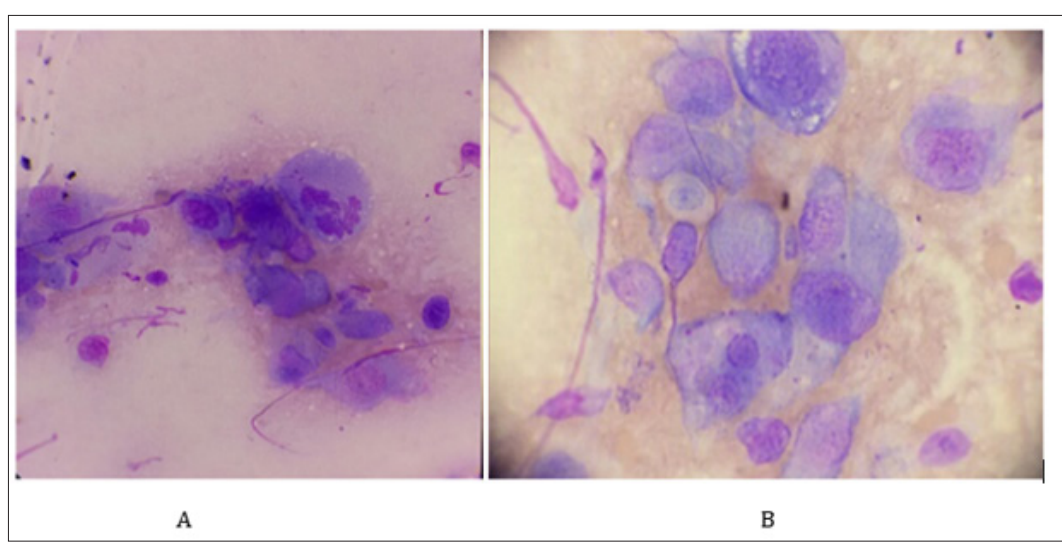

Figure 2: Pleomorphic cell cluster with multiple nuclei and nucleoli. The Cytoplasm was basophilic and contain vacuoles. Leishman Staining.

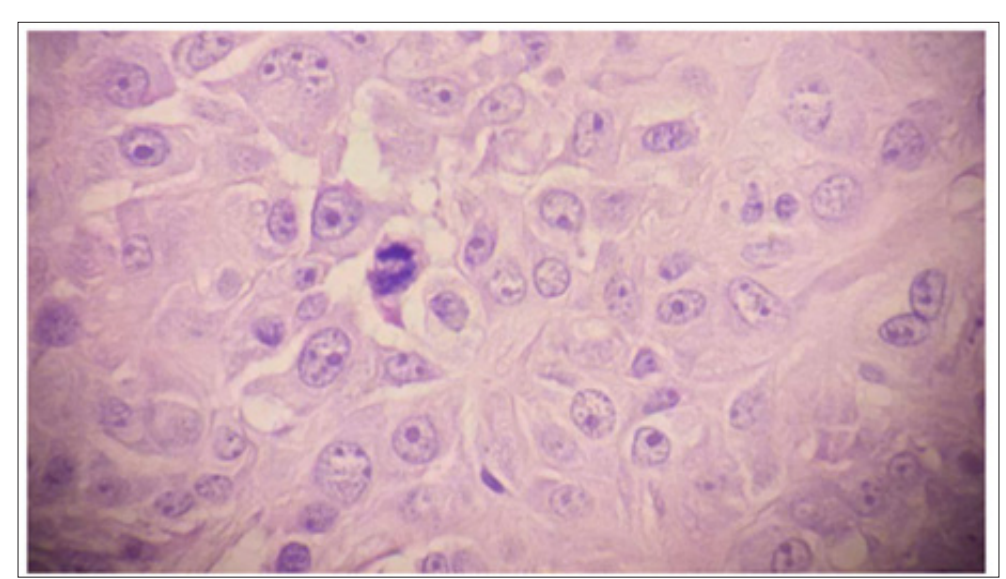

Figure 3: Irregularly arranged round to oval neoplastic cells are enclosed in osteoid matrix.

1-2 prominent nucleoli and atypical mitotic figures can be seen. $\mathrm{H} \& \mathrm{E}$ staining.

\section{Discussion and Conclusion}

Surgical management is the first method of treatment and it is often the preferable method as it increases survival rate, brings pain relief and importantly delays euthanasia [3]. In this case complete surgical removal was not a possibility therefore, wide surgical resection of the tumor with adjuvant chemotherapy was recommended. But owner declined giving chemotherapy and requested for surgical resection of the tumor. In these types of cases where surgical removal is difficult because of the location of the tumor, local recurrence is a common possibility [10]. Postoperative management was done with appropriate antibiotics and supportive therapy. Signs like head pressing were 
gradually reduced and appetite was improved. As owner did not want to start chemotherapy, patient was managed alone with antibiotics, analgesics and supportive therapy. However, patient died few months later since the initial presentation. Treatment of osteosarcoma includes surgery, radiotherapy and chemotherapy. Commonly used chemotherapeutic agents are carboplatin, cisplatin, and doxorubicin. In order to increase the effectiveness of chemotherapy two cytostatic drugs can be given in alternative schedule [3]. Osteosarcomas, according to the WHO classification, are classified on the basis of their localization either in skeletal or extraskeletal tissue [5].

This case illustrates an extraskeletal osteosarcoma originated in the subcutaneous tissue of the head in a dog providing the fact that osteosarcoma can be present in various forms in various locations. Therefore, it should be considered in the differential diagnosis of other primitive mesenchymal tumors of the subcutaneous tissue. It is highly recommended to use advance diagnostic tests to rule out primary bone tumors and tumors arise from the periosteum of the bones like Multilobular Osteochondrosarcoma (MLO) which is a common tumor known to be developed in the skull. Radiographically, MLO can be differentiated from Extraskeletal Osteosarcoma as it has characteristic lobulated appearance which is known as "Pocorn" appearance with evident lysis of bone [10]. Histologically, MLO can be identified by the presence of multiple lobules containing osteoid or cartilage in the center that were separated by thick fibrous septae $[11,12]$. The etiopathogenesis of this tumor is still unclear even in human medicine, where it has been identified in tissues previously treated with radiotherapy for other types of neoplasms. This has been described as radiationinduced extraskeletal osteosarcoma, and it usually develops within 4 years after a high dose of radiation [5].

Traumatic lesions have also been hypothesized to be involved in the pathogenesis of extraskeletal osteosarcoma. There are previously described cases in which extraskeletal osteosarcoma had been developed secondarily to subcutaneous injections and retained surgical sponge $[13,14]$. Especially in cats, vaccineassociated, surgical site related and trauma induced osteosarcoma had been reported $[15,16]$. These unusual tumors presumed to be originated from undifferentiated mechenchymal cells with Osteogenic potential which are commonly known as inducible osteogenic precursor cells (IOPCs) [16]. Chronic inflammation characterized by release of multiple cytokines, makes a favorable environment for malignant transformation of these primitive mecencymal cells [16]. Interestingly, in this case, history revealed an injury caused by a porcupine quill at the same location where tumor had been developed. However, further in-vitro and invivo studies regarding extraskeletal Osteosarcoma in the field of veterinary medicine are needed. Extraskeletal osteosarcoma is associated with a poor prognosis with high rates of metastasis. The purpose of this report was to describe a rare presentation of Extraskeletal osteosarcoma occurring at a site of prior injury in a dog.

\section{Acknowledgement}

The authors wish to thank staff of City Pet Animal Hospital, 137/1, Kaduwela Road, Athurugiria, Sri Lanka.

\section{References}

1. Aguadoa XE, Goyenvallea E, Guintard A (2014) case of polyostotic osteosarcoma with kidney metastases in a dog. Histopathology and microcomputed tomographic analysis: Morphologie 98(323): 187-192.

2. Sternberg RA, Pondenis HC, Yang X, Mitchell MA, O Brien RT, et al. (2013) Association between Absolute Tumor Burden and Serum Bone-Specific Alkaline Phosphatase in Canine Appendicular Osteosarcoma Journal of Veterinary Internal medicine 4(27): 955-963.

3. Szewczyk M, Lechowski R, Zabielska K (2015) What do we know about canine osteosarcoma treatment? - Review. Veterinary Research Communications 39(1): 61-67.

4. Almela R, von Bomhard W, Ansón A, Mayer U (2017) Subcutaneous extraskeletal osteosarcoma in a metatarsal footpad in a cat. Journal of Veterinary dermatology 28(5): 524-e129.

5. Leonardi L, Roperto F, Franciosini MP and Mandara MT (2012) An Unusual Case Report of Primitive jejuneal Canine Osteosarcoma. Internal journal of veterinary science 1(2): 69-71.

6. Langenbach A, Anderson MA, Dambach DM, Sorenmo KU, Shofer FD, et al. (1998) Extraskeletal osteosarcomas in dogs: a retrospective study of 169 cases (1986-1996). Journal of the American Animal Hospital Association 34(2): 113-120.

7. Ringenberg MA, Neitzel LE, Zachary JF (2000) Meningeal Osteosarcoma in a Dog. Journal of Veterinary Pathology 37(6): 653-655.

8. Patnaik AK (1990) Canine Extraskeletal Osteosarcoma and Chondrosarcoma: a Clinicopathologic Study of 14 Cases. Journal of Veterinary Pathology 27(1): 46-55.

9. Spugnini EP, Ruslander D, Bartolazzi A (2001) Extraskeletal osteosarcoma in a cat. Journal of American veterinary medical association 219(1): 6062.

10. Leonardi L, Carrano A, Floris M (2014) Multilobular tumor of the zygomatic bone in a dog. Open Veterinary Journal 4(1): 9-11.

11. Vassilios Psychas, Panayiotis Loukopoulos, Zoe S, Polizopoulou, Georgios Sofianidis, et al. (2009) Multilobular tumour of the caudal cranium causing severe cerebral and cerebellar compression in a dog. Journal of Veterinary Science 10(1): 81-83.

12. Jinelle A, Webb, Julius M, Liptak, Saundra A, et al. (2009) Multilobular osteochondrosarcoma of the os penis in a dog. The Canadian Veterinary Journal 50(1): 81-84.

13. Laura E, Selmic, Lynn R, Griffin, Megan H, et al. (2016) Treatment of extraskeletal osteosarcoma at a previous injection site resulting in prolonged survival in 1 dog. Can Vet J 57(9): 950-954.

14. Margaret A, Miller, Rhonda L, Aper, Amy Fauber, et al. (2006) Extraskeletal osteosarcoma associated with retained surgical sponge in a dog. J Vet Diagn Invest 18(2): 224-228.

15. Groskopf BS, Dubielzig RR, Beaumont SL (2010) Orbital extraskeletal osteo-sarcoma following enucleation in a cat: A case report. Vet Ophthalmol 13(3): 179-183.

16. Wallace B Morrison (2008) Extraskeletal tumors of bone. North American Veterinary Conference pp. 19-23. 


\section{ISSN: 2574-1241}

DOI: 10.26717/BJSTR.2018.07.001470

W Sugandhika Gothami. Biomed J Sci \& Tech Res

This work is licensed under Creative Commons Attribution 4.0 License

Submission Link: https://biomedres.us/submit-manuscript.php

BIOMEDICAL
RESEARCHES $\quad \begin{aligned} & \text { Assets of Publishing with us } \\ & \text { - Global archiving of articles }\end{aligned}$

